UDC: 811.134 .13373 .611

DOI: https://doi.org/10.18485/beoiber.2017.1.2

\author{
Joaquim Juan-Mompó Rovira' \\ Conselleria d'Educació de la Generalitat Valenciana \\ España
}

\title{
ELS REFLEXOS DEL SUFIX LLATÍ -ĬTİA EN CATALÀ
}

\begin{abstract}
Resum
En aquest article hem estudiat l'evolució doble, a -ea i -esa, del sufix llatí -ĬTIİ en català (PAUPERITTİA $>$ pobrea, pobresa), prenent en consideració l'estat medieval de la llengua, la distribució dialectal de cada terminació i les possibles raons que propiciaren l'hegemonia de cadascuna d'elles. Per a conéixer l'estat real d'aquestes dues terminacions en català antic i la seua evolució n'hem analitzat el comportament en un elenc de 23 obres, a fi i efecte d'establir el nombre d'ocurrències de cada terminació, la seua predominança segons la zona dialectal on s'ubiquen els títols analitzats i les preferències, si n'hi ha, de determinats lexemes per una o altra terminació. Els resultats són que totes dues terminacions eren corrents $i$ antigues en català medieval, que no n'hi ha una que anticipe l'altra, i que sí que es detecten preferències territorials (més puixança del sufix -esa com més al nord, i predomini de -ea al sud de l'àrea lingüistica catalana). A tall de conclusió, hem proposat un factor fonètic (el vocalisme, en concret les realitzacions de $a \mathrm{i} e$ ) com a possible element decisiu en l'assentament d'un o l'altre sufix, a més de l'influx de l'adstrat occità com a incentiu del sufix -esa.
\end{abstract}

Paraules clau: Sufixos catalans - ea i -esa, distribució dialectal i literària antiga de sufixos catalans, predomini modern de sufixos catalans, vocalisme àton català, $-s$ - antihiàtica, adstrat occità.

\section{THE DERIVATIVES OF THE LATIN SUFFIX -ǏTİA IN CATALAN}

\begin{abstract}
The article studies the double evolution, to -ea and -esa, from the Latin suffix -ॉTIॅA in Catalan (PAUPERITIIA > pobrea, pobresa), taking into account the state of the medieval language, dialectal distribution of each ending and possible reasons that cause the hegemony of each one. In order to know the actual state of these two morphemes in Old Catalan and its evolution we have analyzed its behavior on a corpus of 23 works, in order to establish the number of occurrences of each suffix, its predominance depending on the dialectal area which houses the titles analyzed and preferences, if any, of certain lexemes for either ending. The results are that both endings were common and ancient in medieval Catalan, that there is not one which takes occurs earlier than the other, and that it is possible to detect territorial preferences (higher frequency of the suffix -esa further north and predominantly -ea of the south of the
\end{abstract}

1 joaquim.juan@uv.es 
Catalan linguistic area). In conclusion, we have proposed a phonetic factor (the vowel system, in particular realizations of $a$ and $e$ ) as a possible key element in the establishment of one or another suffix, as well as the influence of the Occitan adstratum as an incentive of the -esa suffix.

Key words: Catalan suffixes -ea, -esa, literary and dialectal old distribution of Catalan suffixes, modern predominance of Catalan suffixes, unstressed Catalan vowels, -s- eliminating hiatus, Occitan adstratum.

\section{Preliminars}

Una singularitat de la morfologia nominal catalana és l'evolució del sufix llatí -ǏTIIA, que produí els reflexos -ea i -esa (així, PAUPERǏTǏA > pobrea, pobresa), emprats en la formació de noms deadjectivals. Només cal veure una entrada qualsevol del Diccionari català-valencià-balear en què apareguen aquests sufixos (per exemple, pobresa; v. DCVB, VIII: 687) per adonar-se d'aquesta doble evolució, que actualment es concreta en dues àrees diatòpiques: d'una banda, el valencià $i$ algunes zones del sud i de l'occident de Catalunya (ací, amb un replegament recent), en què sentirem pobrea, bellea, vellea, riquea etc., i de l'altra la resta de l'àrea idiomàtica, en què sentirem pobresa, bellesa, vellesa, riquesa etc. (Badia 1999: 234-235). El procés de creació del sufix -ea guarda relació amb l'evolució del llatí -TĬ-, TĚ- abans de vocal, que en català ha propiciat la pèrdua de la consonant (SATIŌNE > saó, PǓTĚU > pou).

Hem d'advertir tanmateix que la llengua estàndard actual dóna prioritat al reflex amb element consonàntic, inclús en la variant valenciana. No obstant això, el recentment publicat Diccionari Normatiu Valencià confereix també caràcter normatiu als noms que acaben en -ea: "pobresa (o pobrea)" etc.

Però fora de la dita variant, el sufix -ea es percep com un arcaisme que perviu arraconat en valencià $\mathrm{i}$ que ha reculat en la resta de l'àrea idiomàtica, malgrat que el trobem sovint en autors de qualsevol procedència territorial des dels primers testimoniatges escrits en llengua catalana. Per deixar-ne constància, hem realitzat una recerca dels reflexos del sufix -ǏTİA en 23 textos catalans i valencians, compresos entre el segle XIII $\mathrm{i}$ el XVI. Els indiquem en l'apartat de fonts i bibliografia.

\section{Estudi de les fonts}

Tot seguit reproduirem els noms que contenen els reflexos estudiats (en primer lloc, els formats amb el sufix -ea i plural -ees, i, després, els formats amb el sufix -esa i plural eses), les obres en què apareixen (cal consultar el repertori de fonts final), el nombre d'ocurrències entre parèntesis $\mathrm{i}$, després del signe $[=]$, la suma total.

Noms formats amb el sufix -ea i plural -ees.

BEOIBERÍsTICA Vol. I N Número 1 (2017) | 27-42 
1) Abtea: Valeri (1), Espill (1), Tirant $(4)^{2}=6$

2) Altea: Valeri (6), Somni (2), Espill (1), Menyspreu (1), Vita (4), Recull (10), Vides (1), ${ }^{3}$ Epistolari (2). Altees: Vita (3) $=29$.

3) Arispea: ${ }^{4}$ Espill (1). Asprea: Espill (1), Recull (1). Asprees: Recull (1) $=4$.

4) Avarea: Homilies (3).

5) Avinentea: Espill (3), Vita (2), Corella (1), Tirant (2), Somni JJ (1), Feits (2) = 11.

6) Avolea: Feits (2) ${ }^{5}$.

7) Baixea: Vita (1), Corella (2) $=3$.

8) Bellea: Valeri (24), Espill (2), Imitació (1), Menyspreu (2), Vita (6), Corella (74), Tirant (100), Recull (3), Caterina (1), Procés (1), March (2), Regiment (3). Bellees: Boeci (1), March (1), Vides (1) = 222.

9) Bonea: Valeri (7), Espill (1), Menyspreu (5), Vita (9), Tirant (3), Recull (1), Consells $(1)$, Feits (2) $=29$.

10) Bravea: Espill (3), Càrcer (1) $=4$.

11) Cativea: Feits (1).

12) Clarea: Espill (1).

13) Destrea: Espill (4), Tirant (1), Caterina (1), Càrcer (1) $=7$.

14) Durea: Valeri (1), Menyspreu (1) $=2$.

15) Espessea: Feits (1).

16) Etiguea: ${ }^{6}$ Espill (1).

17) Expertea: Corella (2).

18) Fadrinea: Espill (2), Recull (2) $=4$.

19) Ferea: Corella (6), Tirant (2), Consells (1), Procés (1), Somni JJ (1), March (16) = 27.

20) Flaquea: Valeri (3), Imitació (1), Menyspreu (1), Vita (12), Corella (4), Tirant (9), Càrcer (4), Feits (4), Epistolari (1) = 39.

21) Fluixea: Espill (2).

22) Fortalea: Valeri (43), Imitació (1), Vita (14), Corella (1), Tirant (9), Procés (1), March (1), Regiment (1), Càrcer $(8)=79$.

23) Franquea: Valeri (5), Espill (1), Vita (3), Tirant (1), Epistolari (2). Franquees: Feits (3), Epistolari (5) $=20$.

24) Freulea: ${ }^{7}$ Vides (1).

25) Gentilea: Espill (1), Corella (1), Tirant (58), Caterina (1), Col·loquis (5), March (1), Carcer (14). Gentilees: Tirant (1) $=82$.

\footnotetext{
2 En un cas escrit "aptea».

${ }^{3}$ Escrit "autea".

${ }^{4}$ Variant de asprea (DCVB, I: 862).

${ }^{5}$ En un cas escrit "aulea".

${ }^{6}$ Nom no registrat en el $D C V B$ ni en $D E C L C$. Deu derivar de ètic, 'molt flac, tísic'.

7 'Debilitat, flaquesa'. Variant de frevolesa, derivat de frèvol (DCVB, VI: 59).
} 
26) Granea: Valeri (6), Espill (1), ${ }^{8}$ Imitació (7), Menyspreu (1), Vita (3), Corella (14), Tirant (16), Recull (1) $=49$.

27) Grossea: Vita (1).

28) Infantea: Valeri (1), Espill (1), Vita (1), Recull (1), March (1), Curial (1), Feits (1) = 7 .

29) Llarguea: Corella (3).

30) Llegea: Valeri (1), Menyspreu (2), Corella (24), Tirant (4), Consells (1), March (1), Càrcer (1). Llegees. Boeci (1), Corella (3), Feits (1) $=39$.

31) Llonguea: Tirant (1), Feits (1) $=2$.

32) Macipea: Homilies (1).

33) Madurea: Tirant (1).

34) Magrea: Tirant (1).

35) Malea: Valeri (1), Espill (4), Menyspreu (1), Tirant (1), Feits (1), Vides (1), Epistolari (1). Malees: Menyspreu (1), Vita (1) $=12$.

36) Malvadea: Vides (1).

37) Mesquinea: Menyspreu (3). Mesquinees: Menyspreu (2) $=5$.

38) Mollea: Espill (1), Corella (1) $=2$.

39) Naturalea: Imitació (1), Tirant (2), Càrcer (2), Feits (9) = 14.

40) Noblea: Valeri (8), Espill (1), Menyspreu (1), Corella (1), Tirant (39), Recull (2), Consells (1), Regiment (1), Càrcer (5), Feits (2), Epistolari (5) $=66$.

41) Ninea: Feits (4).

42) Pansea: Vides (2). ${ }^{9}$

43) Parlitiquea: ${ }^{10}$ Espill (1).

44) Peguea: Valeri (1), March (1) $=2$.

45) Perea: Valeri (5), Espill (11), Imitació (1), Vita (1), Tirant (1), Consells (1), Caterina (1), March (1), Feits (1) $=23$.

46) Plenea: Vides (1).

47) Pobrea: Valeri (7), Somni (1), Espill (2), Vita (21), Recull (8), Regiment (1), Epistolari (5). Pobrees: Recull (1) $=46$.

48) Poquea: Feits (1), Epistolari (1) $=2$.

49) Pregonea: Valeri (6), Tirant (1). Pregonees: Valeri (1) $=8$.

50) Privadea: Vita (1), Recull (1) $=2$.

51) Promptea: ${ }^{11}$ Espill (1).

52) Riquea: Valeri (2), Espill (2), Vita (5), Corella (2), Tirant (20), March (1), Càrcer (2). Riquees: Valeri (8), Boeci (1), Imitació (1), Vita (7), Corella (6), Tirant (1), March (1), Regiment (2) $=61$.

53) Saviea: Valeri (9), Espill (1), Menyspreu (2), Epistolari (9). Saviees: Epistolari (1) $=22$. 54) Simplea: Espill (2), Recull (4) $=6$.

\footnotetext{
8 Escrit "grandea".

${ }^{9}$ En un cas escrit "pensea".

10 'Paràlisi', variant de paralitiquea (DCVB, VIII: 219).

1 "Escrit "promtea".
}

BEOIBERÍSTICA Vol. I / Número 1 (2017) | 27-42 
55) Soltea: Espill (1).

56) Subtilea: Tirant (1), March (1) $=2$.

57) Tendrea: Vita (1).

58) Tisiguea: ${ }^{12}$ Espill (1).

59) Tristea: Recull (1).

60) Vellea: Valeri (5), Espill (2), Vita (2), Corella (7), Tirant (6), Recull (5), Procés (5), Somni JJ (6), March (1), Càrcer (3) = 42.

61) Vivea: Espill (1).

62) Xiquea: ${ }^{13}$ Vita (1).

Noms formats amb el sufix -esa i plural -eses.

1) Abtesa: Tirant (3), Curial (3). ${ }^{14}$ Abteses: Curial (1) $=7$.

2) Agudesa: Col·loquis (1).

3) Altesa: Vita (22), Tirant (302), Somni JJ (8), Col·loquis (2), Curial (3), Regiment (2), Epistolari (4). Alteses: Vita (1), Tirant (1), Epistolari (1) $=346$.

4) Aspresa: Curial (2).

5) Avaresa: Homilies (1). ${ }^{15}$

6) Avinentesa: Somni (1), Curial (12), Epistolari (1) = 14 .

7) Baixesa: Col-loquis (1).

8) Bellesa: Somni (5), Espill (1), Imitació (6), Curial (63), Regiment (3), ${ }^{16}$ Vides (1). Belleses: Imitació (5), Curial (4), Regiment (1) = 89.

9) Bonesa: Somni (1), March (2), Regiment (9) $=12$.

10) Cobesa: Homilies (1), ${ }^{17}$ Vides (2). ${ }^{18}$ Cobeses. Homilies $(1)^{19}=4$.

11) Cruesa: Feits (1).20

12) Destresa: Col·loquis (3), ${ }^{21}$ Curial $(1)=4$.

13) Devesa:22 Caterina (1).

14) Duresa: Vides (1).

15) Flaquesa: Valeri (1), Espill (2), Imitació (4), Col·loquis (1). Flaqueses. Imitació (1) = 9.

12 'Hemorroides', variant de tisiquesa (DCVB, X: 314).

${ }^{13}$ Escrit "chiquea".

${ }^{14}$ En un cas escrit "aptesa".

${ }^{15}$ Escrit "avareza".

16 En un cas escrit "bellessa”.

17 Escrit "cobeeza".

${ }^{18}$ En un cas escrit "cobeesa”.

19 Escrit "cobeezes".

${ }^{20}$ Escrit "crueza".

${ }^{21}$ En dos casos "destreza".

22 L'incloem perquè a Artà, illa de Mallorca, hi ha el topònim Sa Devea, pronunciat $[\Delta \leftrightarrow \cup \varpi \leftrightarrow](D C V B$, IV: 383). 
16) Fortalesa: Somni (1), Imitació (5), Col·loquis (5), ${ }^{23}$ March (1), Curial (4), Regiment (9). Fortaleses: Tirant (1), Col·loquis (1) ${ }^{24}=27$.

17) Franquesa: Valeri (13), Curial (1). Franqueses: Tirant (2), Col-loquis (1) $=17$.

18) Gentilesa: Valeri (1), Espill (1), Recull (29), Somni JJ (1), Curial (1), Càrcer (1). Gentileses: Col·loquis $(1)=35$.

19) Granesa: Somni (1), Imitació (6), Col·loquis (2), ${ }^{25}$ Curial (2), ${ }^{26}$ Càrcer (2), ${ }^{27}$ Feits (1) ${ }^{28}$ $=14$.

20) Greixesa: Col·loquis (1).

21) Horresa: Homilies (2). ${ }^{29}$

22) Lindesa: Tirant (1).

23) Llarguesa: Espill (1), Tirant (1), Curial (5) $=7$.

24) Llegesa: Somni (1), Imitació (1), Regiment (4) $=6$.

25) Llonguesa: Curial (8).

26) Malesa: Tirant (6), March (1), Homilies (1). ${ }^{30}$ Maleses: Vita (4), Tirant (2), Somni JJ (1), Epistolari (1) = 16 .

27) Naturalesa: Col·loquis (2). ${ }^{31}$

28) Nedesa: Vides (1).

29) Noblesa: Somni (1), Espill (1), Tirant (11), Col·loquis (3), Regiment (9), ${ }^{32}$ Epistolari (1). Nobleses. Espill (1), ${ }^{33}$ Tirant (2), Regiment (3) $=32$.

30) Peguesa: March (1). Pegueses: Somni (1) $=2$.

31) Peresa: Imitació (1), Menyspreu (1), March (2), Curial (4), Regiment (1) = 9 .

32) Pobresa: Imitació (6), Tirant (2), Col·loquis (1), ${ }^{34}$ Epistolari (1) $=10$.

33) Poquesa: Somni (1).

34) Privadesa: Somni (1), Curial (2) $=3$.

35) Riquesa: Valeri (1), Tirant (6), March (5), Curial (4), Regiment (1), ${ }^{35}$ Feits (1). Riqueses: Valeri (27), Somni (3), Imitació (20), Corella (4), Tirant (17), March (3), Curial (11), Regiment (10), Vides $(2)^{36}=115$.

36) Saviesa: Valeri (12), Somni (9), Imitació (18), Vita (28), Corella (2), Tirant (73), Procés (1), March (5), Regiment (14), ${ }^{37}$ Homilies (1), ${ }^{38}$ Vides (1), Epistolari (8) $=172$.

\footnotetext{
${ }^{23}$ Escrits "fortaleza".

${ }^{24}$ Escrit "fortalezes".

25 Escrit "grandesa".

${ }^{26}$ En un cas escrit "grandesa".

27 Escrit "grandesa".

${ }^{28}$ Escrit "grandesa".

${ }^{29}$ Escrit “oreeza”. 'Horror'. Variant de horrea, derivat de l'adjectiu hòrreu, hòrrea (DCVB, VI: 553).

30 Escrit "maleza”.

${ }^{31}$ En un cas escrit "naturaleza".

32 En sis casos escrit "nobleça".

${ }^{33}$ Escrit "noblesses".

${ }^{34}$ Escrit "pobreza".

${ }^{35}$ Escrit "requesa".

${ }^{36}$ En un cas escrit "riquezes".
} 
37) Subiranesa: Tirant (1).

38) Subtilesa: Tirant (1), March (1) ${ }^{39}=2$.

39) Vellesa: Curial (10), Feits (1), ${ }^{40}$ Vides $(1)=12$.

40) Vilesa: Imitació (1).

Comptat i debatut, els lexemes que seleccionen el sufix -ea i plural són 62 , mentre que els que seleccionen el sufix -esa i plural són 40.

Tot seguit comparem els resultats dels lexemes que han seleccionat les dues terminacions; el número entre parèntesis indica les ocurrències, i també entre parèntesis aportem la diferència entre les ocurrències primeres $i$ les segones.

abtea (6) abtesa, abteses (7) (diferència +1 de -esa)

altea, altees (29) altesa, alteses (346) (diferència +317 de -esa)

asprea, asprees (3) aspresa (2) (diferència +1 de -ea)

avinentea (11) avinentesa (14) (diferència +3 de -esa)

baixea (3) baixesa (1) (diferència +2 de -ea)

bellea, belles (222) bellesa, belleses (89) (diferència +133 de -ea)

bonea (29) bonesa (12) (diferència +17 de -ea)

destrea (7) destresa (4) (diferència +3 de -ea)

flaquea (39) flaquesa, flaqueses (9) (diferència +30 de -ea)

fortalea (79) fortalesa, fortaleses (27) (diferència +52 de -ea)

franquea, franquees (20) franquesa, franqueses (17) (diferència +3 de -ea)

gentilea, gentilees (82) gentilesa, gentileses (35) (diferència +47 de -ea)

granea (49) granesa (14) (diferència +35 de -ea)

llarguea (3) llarguesa (7) (diferència +4 de -esa)

llegea, llegees (39) llegesa (6) (diferència +33 de -ea)

Ilonguea (2) Ilonguesa (8) (diferència +6 de -esa)

malea, malees $(12) \sim$ malesa, maleses $(16)$ (diferència +4 de -esa)

naturalea (14) naturalesa (2) (diferència +12 de -ea)

noblea (66) noblesa, nobleses (32) (diferència +34 de -ea)

peguea (2) peguesa, pegueses (2) (diferència 0)

perea (23) peresa (9) (diferència +14 de -ea)

pobrea, pobrees (46) pobresa (10) (diferència+ $36 \mathrm{de}-e a)$

poquea (1) poquesa (1) (diferència 0$)$

privadea (2) privadesa (3) (diferència +1 de -esa)

riquea, riquees $(61) \sim$ riquesa, riqueses $(115)$ (diferència +54 de -esa)

\footnotetext{
37 Un cas escrit "sabiesa".

38 Escrit "savieza".

39 Escrit "suptilesa".

40 Escrit "veylesa".
} 
saviea, saviees $(22) \sim$ saviesa (172) (diferència +150 de -esa)

subtilea (2) subtilesa (2) (diferència 0 )

vellea (42) vellesa (12) (diferència +30 de -ea)

Vist això, observem els lexemes en què hi ha més diferències a favor del sufix -ea (i -ees) són:

bellea, belles (222) bellesa, belleses (89) (diferència: +133 de -ea)

fortalea (79) fortalesa, fortaleses (27) (diferència: +52 de -ea)

gentilea, gentilees (82) gentilesa, gentileses (35) (diferència: +47 de -ea)

pobrea, pobrees (46) pobresa (10) (diferència: +36 de -ea)

granea (49) granesa (14) (diferència: +35 de -ea)

noblea (66) noblesa, nobleses (32) (diferència: +34 de -ea)

llegea, llegees (39) Ilegesa (6) (diferència: +33 de -ea)

Mentre que els lexemes en què hi ha més diferències a favor del sufix -esa (i -eses) són:

altea, altees (29) altesa, alteses (346) (diferència: +317 de -esa)

saviea, saviees (22) saviesa (172) (diferència: +150 de -esa)

riquea, riquees $(61)$ riquesa, riqueses (115) (diferència: +54 de -esa)

Comprovem, a més, que els lexemes que només seleccionen un sufix prefereixen seleccionar el sufix -ea (32 casos) enfront del sufix -esa (7 casos):

a) Presenten el sufix -ea (i plural): bravea, cativea, clarea, espessea, etiguea, expertea, fadrinea, ferea, fluixea, freulea, grossea, infantea, macipea, madurea, magrea, malvadea, mesquinea, mollea, ninea, pansea, parlitiquea, plenea, pregonea, promptea, simplea, soltea, subtilea, tendrea, tisiguea, tristea, vivea, xiquea (32 casos).

b) Presenten el sufix -esa (i plural): agudesa, greixesa, horresa, lindesa, nedesa, subiranesa, vilesa (7 casos).

Les dades anteriors remarquen la supremacia del sufix -ea en català medieval, que seleccionava més lexemes i presentava més casos de diferència al seu favor.

Quant a l'estudi de les aparicions dels sufixos en les obres analitzades (de les quals hem triat les més representatives atenent a factors diatòpics i diacrònics, i evitant les obres poètiques, per si la rima intervenia en la selecció de les terminacions; també hem descartat les traduccions, per si els sufixos castellans -ez o -eza condicionaven la selecció del sufix català), constatem els següents resultats:

a) Valeri. Sufix -ea: abtea (1), altea (6), bellea (24), bonea (7), durea (1), flaquea (3), fortalea (43), franquea (5), granea (6), infantea (1), Ilegea (1), malea (1), noblea (8), 
peguea (1), perea (5), pobrea (7), pregonea (6), pregonees (1), riquea (2) i riquees (8), saviea (9), saviesa (12), vellea (5). Sufix - esa: flaquesa (1), franquesa (13), gentilesa (1), riquesa (1) i riqueses (27), saviesa (12). Resultat: 163 en -ea i 55 en -esa.

b) Somni. Sufix -ea: avinentea (1), pobrea (1). Sufix -esa: bellesa (5), bonesa (1), fortalesa (1), granesa (1), llegesa (1), noblesa (1), pegueses (1), poquesa (1), privadesa (1), riqueses (3), saviesa (9), vellesa (5). Resultat: 2 en -ea i 30 en -esa.

c) Tirant. Sufix -ea: abtea (3), aptea (1), avinentea (2), bellea (100), bonea (3), destrea (1), ferea (2), flaquea (9), fortalea (7), franquea (1), gentilea (58) i gentilees (1), granea (16), llegea (4), Ilonguea (1), madurea (1), magrea (3), malea (1), naturalea (2), noblea (39), perea (1), pregonea (1), riquea (20) i riquees (1), subtilea (1), vellea (6). Sufix - esa: abtesa (3), altesa (302) i alteses (1), fortaleses (1), franqueses (2), gentilesa (29), lindesa (1), Ilarguesa (1), malesa (6) i maleses (2), noblesa (11) i nobleses (2), pobresa (2), riquesa (6) i riqueses (17), saviesa (73), subiranesa (1), subtilesa (1). Resultat: 235 en -ea i 460 en -esa.

d) Curial. Sufix -ea: granesa (1), infantea (1). Sufix -esa: abtesa (2) i abteses (1), altesa (3), aptesa (1), aspresa (2), avinentesa (12), bellesa (63) i belleses (4), destresa (1), fortalesa (4), franquesa (1), gentilesa (1), granesa (1), grandesa (1), graveses (1), Ilarguesa (5), llonguesa (8), peresa (4), privadesa (2), riquesa (4) i riqueses (11), vellesa (10). Resultat: 2 en -ea i 142 en -esa.

e) Feits. Sufix -ea: avinentea (2), avolea (1), aulea (1), bonea (2), cativea (2), espessea (1), flaquea (4), franquees (3), granea (1), infantea (1), Ilonguea (1), magrea (1), naturalea (9), ninea (4), noblea (2), perea (1), poquea (1), riquea (2). Sufix -esa: cruesa (1), riquesa (1), vellesa (1). Resultat: 39 en -ea i 3 en -esa.

f) Homilies. Sufix - ea: avarea (3), macipea (1). Sufix -esa: avaresa (1), cobesa (1) i cobeses (1), malesa (1), horresa (2), saviesa (1). Resultat: 4 en -ea i 7 en -esa.

g) Vides. Sufix - ea: autea (1), bellea (1), freulea (1), malea (1), malvadea (1), pansea (2), plenea (1). Sufix -esa: bellesa (1), cobesa (2), duresa (1), nedesa (1), riqueses (2), saviesa (1), vellesa (1). Resultat: 4 en -ea i 9 en -esa.

h) Col-loquis. Sufix -ea: gentilea (5). Sufix -esa: agudesa (1), altesa (8), baixesa (1), destresa (3), flaquesa (1), fortalesa (5) i fortaleses (1), franqueses (1), gentileses (1), grandesa (2), greixesa (1), naturalesa (2), noblesa (3), pobresa (1). Resultat: 5 en -ea i 31 en -esa.

i) Regiment. Sufix -ea: bellea (3), fortalea (1), noblea (1), pobrea (1), riquees (2). Sufix esa: altesa (2), bellesa (2) i belleses (2), bonesa (9), fortalesa (9), llegesa (4), noblesa (7) i nobleses (3), peresa (1), riquesa (1) i riqueses (10), saviesa (14). Resultat: 8 en -ea i 64 en -esa.

j) Imitació. Sufix -ea: bellea (1), flaquea (1), flaquesa (4), fortalea (1), granea (7), granesa (6), naturalea (1), noblea (1), perea (1), riquees (1). Sufix -esa: bellesa (6), belleses (1), flaqueses (1), fortalesa (5), llegesa (1), peresa (1), pobresa (6), riquesa (1), riqueses (20), saviesa (18), vilesa (1). Resultat: 24 en -ea i 61 en -esa. 
k) Menyspreu. Sufix -ea: altea (1), bellea (2), bonea (5), durea (1), flaquea (1), granea (1), llegea (2), malea (1), malees (1), mesquinea (3), mesquinees (2), saviea (2). Sufix -esa: peresa (1). Resultat: 22 en -ea i 1 en -esa.

I) Vita. Sufix -ea: altea (4), altees (3), avinentea (2), baixea (1), bellea (6), bonea (9), xiquea (1), expertea (2), flaquea (12), fortalea (14), franquea (3), granea (3), grossea (1), infantea (1), malees (1), perea (1), pobrea (21), privadea (1), riquea (5), riquees (7), tendrea (1), vellea (2). Sufix -esa: altesa (22), alteses (1), maleses (4), saviesa (28). Resultat: 109 en -ea i 55 en -esa.

m) Epistolari. Sufix -ea: altea (2), avinentesa (1), flaquea (1), franquea (2), franquees (5), malea (1), naturalea (2), noblea (5), pobrea (5), poquea (1), saviea (9), saviees (1). Sufix -esa: altesa (4), alteses (1), maleses (1), noblesa (1), pobresa (1), saviesa (8), savieses (5). Resultat: 35 en -ea i 21 en -esa.

Concloem, doncs, que la provinença valenciana del text suggereix una supremacia del sufix -ea, ja que aquest és majoritari en el Valeri de Canals, en la Vita d'Isabel de Villena, en el Menyspreu de Miquel Peres i en també l'Epistolari; això ocorre inclús en el Tirant, títol en el qual el morfema -esa presenta 460 ocurrències contra les 235 de -ea, tot i que remarquem que en 303 ocurrències -esa apareix en un sol lexema (alt-). No obstant això, valorarem aquesta dada amb prudència, perquè també en el Llibre dels feits la terminació - ea predomina sobre l'altra (39 vs. 2). En la resta de títols, ara de procedència catalana, és -esa, en canvi, el sufix majoritari. La conclusió de tot això és que en el català medieval escrit els dos sufixos eren plenament actius, amb una influència indiscutible de la variant territorial (Badia 1999: 234-235; Gulsoy 1993: 296; Colón 2001: 32-33). ¿Però tenim algun indici sobre com es comportava el català parlat, o el popular?

\section{Estudi de fonts toponímiques i d'altres fonts escrites}

Les dades sobre la toponímia ens diuen que el sufix -ea també existí en zones on després va consolidar-se l'altre sufix. Així, sabem que a la Cerdanya hi hagué un focus antic de -ea, fet constatat per topònims com Roc de Malè (< Malea < MALǏTIIA) (Coromines 1983: 299); igualment, a Artà hi ha l'alqueria Son Fortesa, pronunciat popularment $[\phi o P \cup \tau \leftrightarrow](D C V B, V I: 16)$; i en la mateixa illa, Sa Devesa, pronunciat $[\Delta \leftrightarrow \cup \varpi \leftrightarrow]$ ( $D C V B$, IV: 383). També ens consten verbs arcaics procedents de noms acabats en -ea: el català antic coneixia el doblet enriquir/enriqueir, el primer infinitiu procedia de l'adjectiu ric, mentre que el segon s'originava en el nom abstracte riquea; aquest verb presenta formes cognates en occità, desenvolupades amb una sintervocàlica (enriquezir) (Coromines 1983: 274). Si desplacem l'anàlisi a les llles Balears, veurem que en mallorquí actual es donen variants col-loquials com ara acuar, roegar, camia, lloa, filoa, raboa..., totes amb pèrdua de la s intervocàlica, clara resposta ultracorrectora a la influència dels pobladors occitans medievals. En efecte: els mallorquins coetanis adaptaren i corregiren 
els occitanismes corrents del tipus dizem, plazer, auzir etc. en les formes catalanes diem,

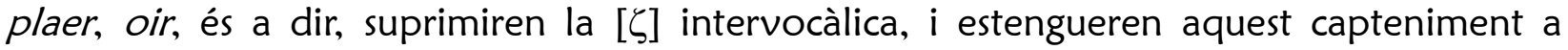
aquells mots, en què la consonant alveolar fricativa sonora és etimològica, no adventícia (Coromines 1983: 257). Pensem que potser eixa ultracorrecció també actuà en el català continental medieval de les zones septentrionals, influït pel contacte amb l'occità. Això pogué afavorir l'èxit momentani de pobrea enfront de pobresa, vista aquesta com a occitanisme (fet que la convivència dels sufixos -ea i -esa en les Vides de sants rosselloneses corrobora). Per un motiu fonètic posterior (antihiàtic) es reintroduí la $s$ intervocàlica. Altres dades que abonen la vivor del hiat -ea- són l'adjectiu actual entremaliat, variació de entremaleat < malea (malesa) (Coromines 1983: 255); en aquest cas, el català oriental resolia la dificultat fonètica que li representava el hiat -eatransformant-lo en -ia-, d'articulació més factible. Ho tractarem més avall.

Però la tendència general del català -amb l'excepció de l'àrea valenciana- ha estat evitar el hiat -ea-; creiem, com hem dit adés, que açò es va veure propiciat en les zones septentrionals per la influència de l'adstrat occità. Ho advertim en un grapat de casos en què es produeixen ultracorreccions, com ara en les procedents de les Homilies d'Organyà: "beneseta" ( < beneeta < beneita < BENEDICTA), "enrequesex" (verb enriqueir < riquea), "vesé" (< veé), "gasardó" (< gaardó), " ${ }^{41}$ "vesent" (< veent), "veser" (< veer), "viso" (< vio $<$ vido < VIDUU) (Coromines 1983: 274, 307, 337, 342, 345, 346, 354). També: "crezen" (< creen "creuen'), "rezebam" (< reebam), "gazardó" (< gaardó), "dizie" (< deïa), "ozí" (< ol), "dezien" (< deïn), "vezer" (< veer), "ozid" (< oït), "crezeg" (< creec 'cregué') (Coromines 1976: 132-149). Aquesta necessitat d'evitar el hiat, notòria en el català septentrional, ${ }^{42}$ es concretà també en la introducció d'altres consonants antihiàtiques, no exclusivament la s sonora: "gadardó" (< gaardó), "avaredes" (< avarees), "redebria" (< reebria), "fedés" (< feés), "radó" (< raó), "vedí" (< veí), "redebre" (< reebre) (Coromines 1976: 132-147). ${ }^{43}$ En mallorquí aquesta funció antihiàtica també pot realitzar-la la consonant labial v: rovella (< roella < rosella), rabova (< raboa < rabosa) (Veny 2003: 151).

En contrast amb els comportaments dialectals exposats, els textos de procedència valenciana o relacionables no defugen el hiat; ho hem verificat en les fonts consultades: "s'aveà a furtar", "aveà's a furtar", "la coloma fo així aveada", "fon veada" (Recull);

41 Schmid 1988: 208 registra en el Blanquerna de Joan Bonllavi les variants amb hiat "guaardó" (< germànic WIDARLON) i "guaardonar"; no serà rar, doncs, que aparega en altres textos o parlars una $s$ sonora intervocàlica.

42 I fins i tot més avall: en textos catalans meridionals també apareixerà aquest reforç antihiàtic: "llampresa", "llampreses" en els Col/loquis de Despuig. O "menyspresa" i "menyspresant" en l'edició barcelonina de la Imitació de Miquel Peres.

43 Inclús trobarem exemples d'aparició de la s sonora antihiàtica en substitució d'una consonant dental etimològica: "devezí” (< devedi) (Coromines 1976: 142). V. també Gulsoy 1993: 142. 
"avear" (Procés); "poble bé aveat" (Regiment); "Montea [< Montesa] e Vallada", "veats", "despees" (Fets); "desvear d'aquests mals vicis" (Somni JJ) etc.

Aquesta dualitat inicial del sistema català anà diluint-se amb el pas del temps, i el sufix -ea esdevingué una peculiaritat valenciana, mentre que a les altres zones de la llengua s'expandia el sufix -esa, fins assolir un prestigi literari major. Aquesta idea ja la preceptuen les Regles de esquivar vocables o mots grossers o pagesívols al condemnar "perea e probea per dir peresa e pobresa, e semblants". Badia 1999: 234-235 conclou sobre aquesta censura: “Defensa de les formes tingudes per més correctes i més pròpies d'un estil elevat [...] contra les populars i dialectals corresponents". Condemna errònia al nostre parer, perquè els noms acabats en -ea o -esa eren igualment populars i dialectals, cadascun en la seua àrea. Una altra cosa és que els autors de les Regles prioritzaren una o l'altra variant.

Però aquest parer no implica la percepció completa del procés de generalització del sufix -esa a costa de -ea. No discutirem que, a més del juí expressat pels autors de les Regles, els gramàtics, lingüistes i filòlegs posteriors hagen marginat massivament la utilització del segon sufix: així, per a Badia 1999: 234, aquest és un "sufix reduït", sorgit com a resultat d'una elisió de la $s$ a partir de la forma primigènia -esa. També Colón 2003: 183 recalca que el sufix -esa representa el "manteniment de la sibilant sonora", com si l'altre haguera evolucionat des d'aquest i haguera perdut la consonant alveolar, més o menys com si es tractara d'un defecte de pronunciació; i continua: "contemplem la competència entre el sufix -esa (< ITIA) i la variant -ea; aquesta última, que també és molt freqüent en el català antic d'altres comarques no valencianes, és la que quasi s'ha imposat a València, i en aquestes cartes ${ }^{44}$ veiem que se'n manifesta la tendència", en què Colón atorga categoria de sufix exclusivament a -esa, mentre que l'altre es limita a ser una variant, una "tendència", no res assentat i consolidat. Els fets demostren que els dos sufixos funcionaven en igualtat de condicions en tots els textos medievals (només hi havia entre ells una diferència qualitativa), sense que puguem discernir una forma primigènia $i$ una altra que en derivara.

Altres lingüistes han enfocat el tema des d'una altra òptica. Així, Sanchis (1950: 86) postula l'acceptació a nivell oral del sufix -ea (com una variant amb elisió de la consonant intervocàlica de -esa), atés que és el sufix estés per tot València. Però això no li impedeix dir que és un arcaisme heretat de la "llengua clàssica". Veiem, en aquesta afirmació, una contradicció, car una forma tan viva com la terminació -ea en valencià no es pot considerar un "arcaisme».

Giner (1998: 509), en canvi, aporta valor a la terminació -ea: “és la normal en valencià i en la llengua antiga, i respon [...] al tractament etimològic [...] en valencià és sentida com a més entranyablement nostrada front al castellà -eza, puix les formes en -esa sonen ací a castellanismes". Pensem que aquesta afirmació és la que més s'acosta a la

${ }^{44}$ Es refereix a l' Epistolari de la València medieval.

BEOIBERÍsTICA Vol. I Número 1 (2017) | 27-42 
realitat, ja que en el català de València el procés històric ha anat en la línia de prioritzar el sufix - ea en perjuí de -esa. Els dos estudis següents palesen aquesta afirmació.

En primer Iloc, Rafanell i Valsalobre (2000: 145), referint-se al contrast entre les dues edicions de l'Espill de la vida religiosa (Barcelona 1515 i València 1529): "Com és ben sabut, la derivació del sufix llatí -ITIA en -ea apareix sempre com una típica marca de valencianitat [...] En l'imprès valencià notem la robustesa de -ea, però no pas el seu ús exclusiu".

En segon lloc, Juan-Mompó (2007) estudia els canvis que introduí el canonge Teodor Tomàs en Verger de la sacratíssima Verge Maria (Barcelona, 1732) i Història $i$ portentosa vida de la extàtica y seràfica verge sancta Catherina de Sena (València, 1736), llibres que ell reedità procedents, respectivament, dels originals medievals Vida de la sacratíssima Verge Maria, de Miquel Peres (València, 1494) i Vida de la seràphica sancta Catherina de Sena, de Ramon de Càpua (trad. catalana de fra Tomàs Vesach) (València, 1511). Les edicions de Tomàs presenten les variants "naturalea", "pobrea, "riquees", "poquesa" i "bellea" en compte de les medievals "natura", "fretura", "riqueses", "pobredat", "poquedat" i "pulcritut". A més d'eixos canvis, Tomàs també afegí glosses, escrites entre parèntesis, a aquelles paraules el significat de les quals devia jutjar de comprensió difícil per als lectors moderns; ho veiem en els casos "tibieça (tibiea)", "tritícia (tristea)" i "fretura (pobrea)". La conclusió és la "Funcionalitat superior de la terminació ea [...] amb deu concurrències, en relació amb la terminació -esa, que només en presenta tres" (Juan-Mompó 2007: 292).

La realitat és que els testimoniatges literaris, siguen cultes o populars, han confirmat l'èxit de la terminació -ea en valencià, mentre que en les altres zones de l'àmbit lingüístic català el sufix reeixit ha estat -esa. ¿Què ha propiciat eixa disparitat? Des del nostre punt de vista, el factor clau pot haver estat fonètic, en concret, l'articulació de la $e$ àtona i la $e$ tònica, i la de la $a$ àtona. ${ }^{45}$ I és que en valencià la distinció de les vocals àtones $a \mathrm{i} e$ permet percebre clarament el hiat en mots com ara vellea; però en els dialectes en què eixa distinció no s'esdevé, cal incorporar una consonant que evite la fusió de les dues síl-labes finals (-ea) en una de sola, per aglomeració de les vocals; això ocorre en els dialectes orientals, que pronuncien $e$ tònica oberta o neutra $+e$ àtona neutra, i en lleidatà i tortosí, que pronuncien $e$ tònica tancada $+e$ àtona oberta. Aquest fet pot explicar el pas vellea a vellesa, paral·lel al de idea a ideia, veem a veiem etc.., o als ja exposats i documentats veer a veser, raó a rasó etc. Hem observat així mateix que en balear, quan el contacte es realitza entre vocals distintes a $e$, $a$, el hiat està garantit i s'arriba a elidir la consonant alveolar: raboa, camia etc. En la gènesi d'aquesta $s$ antihiàtica, nascuda per a evitar la monoftongació -ea $\rightarrow-\dot{e}$, podria haver col·laborat també una influència d'adstrat occitana activa al nord de Catalunya, ja que en els textos

45 Gulsoy 1993: 52-53 s'ocupa de les es en català segons dialectes i la seua evolució, especialment la - $e$ àtona final en català occidental i valencià. 
medievals septentrionals trobem, com ja hem apuntat, formes com rasó o veser, escasses o absents més al sud.

\section{Conclusions}

A tall de conclusions, direm que en català medieval hi hagué dues evolucions i una certa indefinició, ja que els dos sufixos convivien en tots els dialectes, amb una preponderància evident del sufix -ea en els textos meridionals. Al remat, al nord i a les Balears es va imposar -esa, i al sud -ea. El factor que propicià eixa divergència pogué ser fonètic: l'articulació de les es àtones i tòniques i de la a àtona. Vegem-ho amb l'exemple de riquea: en oposició al català central $[\rho \imath \cup \kappa E \leftrightarrow]$, al balear $[\rho \imath \cup \kappa \leftrightarrow \leftrightarrow]$ i al català

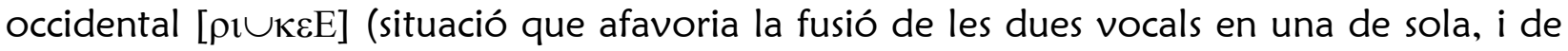
les dues síllabes en una, fet que desfigurava la paraula), el valencià $[\rho i \cup \kappa \varepsilon \alpha]$ donava una articulació que assegurava el hiat; en aquelles zones on això no era possible calia introduir

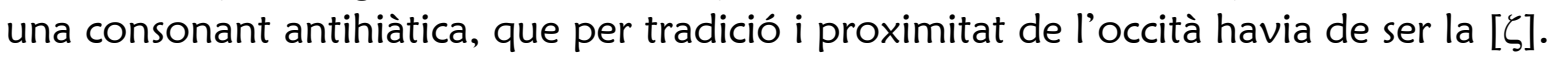

Deia Germà Colón (1958: 296) que sobre aquesta matèria de què ens hem ocupat no teníem prou uelements de judici”. Amb el nostre estudi desitgem haver contribuït a millorar aquesta percepció.

\section{FONTS}

Valeri $=$ Canals, Antoni. Llibre anomenat Valeri Màximo. Barcelona: Impremta L'Avenç, 1914. Imprès.

Somni $=$ Metge, Bernat. Lo somni. Barcelona: Editorial Barcino, 1925. Imprès.

Boeci = Boeci. Libre de consolació de philosophia. Barcelona: Biblioteca Catalana, 1873. Imprès.

Espill = Roig, Jaume. Espill. Barcelona: Editorial Barcino, 2014. Imprès.

Imitació = Peres, Miquel. La imitació de Jesucrist. Barcelona: Impremta L'Avenç, 1911. Imprès.

Menyspreu $=$ Peres, Miquel. Tractat intitulat de menyspreu del món. Barcelona: Impremta L'Avenç, 1911. Imprès.

Vita = de Villena, Isabel. Llibre anomenat Vita Christi. Barcelona: Biblioteca Catalana, 1916. Imprès.

Corella = Roís de Corella, Joan. Obra profana. València: Edicions Tres i Quatre, 1983. Imprès.

Tirant = Martorell, Joanot. Tirant lo Blanch. València: Editorial Tirant lo Blanch, 2004. Imprès. 
Recull = Aguiló i Fuster, Marian (ed.). Recull d'eximplis, gestes e faules e altres ligendes ordenades per $A B C$, tretes de un ms. en pergami de començaments del segle XV, 2 vols. Barcelona: Biblioteca Catalana, 1881. Imprès.

Consells = Pitarch, Vicent i Gimeno, Lluís (ed.). Poesia eròtica $i$ burlesca dels segles $x \mathrm{~V} i$ XVI. València: Edicions 3i4, 1982. Imprès.

Caterina $=$ Rosell, Marina (ed.). "Certamen poètic valencià en llaor de santa Caterina de Sena". Anexos de la Revista Lemir (2005): 1-44. Imprès.

Procés / Somni JJ = Gimeno, Lluís (ed.). Lo procés de les olives. Lo somni de Joan Joan. València: Edicions 3i4, 1998. Imprès.

Col·loquis = Despuig, Cristòfol. Los col/loquis de la insigne ciutat de Tortosa. Barcelona: Imprenta de la Renaixensa, 1877. Imprès.

March = Marc, Ausiàs. Les obres d'Auzias March, 2 vols. Barcelona: Institut d'Estudis Catalans, 1912. Imprès.

Curial = Rubió y Lluch, Antoni (ed.). Curial y Güelfa. Barcelona: Real Academia de Buenas Letras, 1901. Imprès.

Regiment $=$ Eiximenis, Francesc. Regiment de la cosa pública. Barcelona: Editorial Barcino, 1927. Imprès.

Càrcer = Vallmanya, Bernardí. Lo càrcer d'amor. Barcelona: Biblioteca Catalana, 1912. Imprès.

Feits = Jaume I. Llibre dels fets del rei en Jaume. Barcelona: Editorial Barcino, 1991. Imprès.

Homilies = Coromines, Joan (ed.). "Les homilies d’Organyà. Edició crítica millorada i anotada", Entre dos llenguatges, vol. I. Barcelona: Curial, 1976. Imprès.

Vides $=$ Coromines, Joan (ed.). Lleures $i$ converses d'un filòleg. Barcelona: Club Editor, 1983. Imprès.

Epistolari = Rubio Vela, Agustín (ed.). Epistolari de la València medieval. València: Institut de Filologia Valenciana, 1985. Imprès.

\section{BIBLIOGRAFIA}

Badia i Margarit, Antoni Maria. Les Regles de esquivar vocables i "la qüestió de la Ilengua”. Barcelona: Institut d'Estudis Catalans, 1999. Imprès.

Colón, Germà. "Observacions al Diccionari de la rima”. Boletín de la Sociedad Castellonense de Cultura, 34 (1958): 290-305. Imprès.

- Les Regles d'esquivar vocables. Autoria i entorn lingüístic. Barcelona: Institut d'Estudis Catalans, 2001. Imprès.

- De Ramon Llull al Diccionari de Fabra. Acostament lingüístic a les lletres catalanes. Barcelona: Publicacions de l'Abadia de Montserrat, 2003. Imprès. 
Coromines, Joan (ed.). “Les homilies d'Organyà. Edició crítica millorada i anotada”. Entre dos llenguatges, vol. I. Barcelona: Curial, 1976. Imprès.

—. Lleures i converses d'un filòleg. Barcelona: Club Editor, 1983. Imprès.

$D C V B=$ Alcover, Antoni i Moll, Francesc de Borja. Diccionari Català-Valencià-Balear, vols. I-X. Palma de Mallorca: Editorial Moll, 1993. Imprès.

DNV = Diccionari normatiu valencià. Web. 14 gen. 2017.

Giner i Marco, Josep. Obra filològica completa (1931-1991). Paiporta: Denes, 1998. Imprès.

Gulsoy, Joseph. Estudis de gramàtica històrica. València / Barcelona: Institut Universitari de Filologia Valenciana / Publicacions de l'Abadia de Montserrat, 1993. Imprès.

Juan-Mompó, Joaquim. L'obra editada del canonge Teodor Tomàs (València 1677-1748). Estudi lingüístic i edició. València: Universitat de València (CD-ROM. ISBN: 97884-370-6798-8), 2007. Imprès.

Rafanell, August i Valsalobre, Pep (2000): ““Català” i "valencià” al primer Cinccents. A propòsit de dues edicions de l'Espill de la vida religiosa". Caplletra, 27 (2000): 137-165. Imprès.

Sanchis Guarner, Manuel. Gramàtica valenciana. València: Editorial Torre, 1950. Imprès.

Schmid, Beatrice. Les "traduccions valencianes" del Blanquerna (València 1521) i de la Scala Dei (Barcelona 1523). Barcelona: Curial / Publicacions de l'Abadia de Montserrat, 1988. Imprès.

Veny, Joan. Escriptura i oralitat a Mallorca. Mallorca: Editorial Moll, 2003. Imprès. 